\title{
EL PRINCIPIO DE COOPERACION ENTRE LOS ESTADOS $Y$ EL FONDO MONETARIO INTERNACIONAL
}

Miguel de la Lama Eggerstedt

\begin{abstract}
A diferencia del Derecho Internacional clásico que se limitaba a señalar como su objeto fundamental el mantenimiento de la paz y la seguridad internacionales, el Derecho Internacional contemporáneo enfatiza que el logro de dicho objeto implica el crecimiento económico. Asi el Principio de Igualdad Soberana de los Estados es limitado a su acepción de igualdad juridica, mientras se reconoce la desigualdad económica y social existente, y se establecen normas en favor de la categoria es. pecial de "países en desarrollo". Al Principio de Proscripción del uso de la fuerza o de la amenaza del uso de ésta, se añade el Principio de Cooperación que obliga a los Estados a colaborar entre si para lograr el crecimiento económico, particularmente, de los paises en desarrollo.
\end{abstract}

El autor propone el estudio de la vigencia del Principio de Cooperación en la esfera monetaria internacional. Para ello estudia tres aspectos del Fondo Monetario Internacional que han sido especialmente criticados por los paises en desarrollo: La distribución del poder votante; la escasa ligazón entre la creación y distribución de Derechos Especiales de Giro y el desarrollo; y la condicionalidad en la utilización de los recursos del Fondo.

\section{El Principio de Cooperación}

La primera formulación convencional del Principio de Cooperación entre los Estados, se encuentra en los artículos 23 y 24 del Convenio Constitutivo de la Sociedad de las Naciones. Pese a que dicho organismo internacional se caracterizó por su intensa preocupación - al fin frustrada- por evitar las guerras, los artículos indicados se referían ya expresamente, a la cooperación económica y social entre los Estados. 
Durante la segunda guerra mundial, al diseñar las potencias aliadas el nuevo organismo universal, pensaron que éste debería tener no sólo la función de prevenir las agresiones, sino también la función positiva de promover condiciones conducentes a lograr relaciones amistosas entre los Estados, a través de la cooperación económica y social (1). Esta tendencia logró concretarse en las Conferencias de Dumbarton Oaks y, posteriormente, en la Carta de San Francisco.

El artículo 55 de la referida Carta, establece que Naciones Unidas deberá promover niveles de vida más elevados, trabajo permanente para todos, y condiciones de progreso y desarrollo económico y social. El inciso b) del indicado artículo establece asimismo que la Organización promeverá la solución de problemas internacionales de carácter económico, social y sanitario. y de otros problemas conexos (2).

Para alcanzar estos objetivos, las Naciones Unidas opera a través de la Asamblea General, el Consejo Económico y Social -_ECOSOC - y la Secretaria General, asi como, subsidiariamente, a través de los organismos y agencias especializadas. En 1961 la Asamblea General aprobó la Resolución 1710 (XVI) que estableció la primera Década de las Naciones Unidas para el Desarrollo. A partir de entonces la Asamblea General ha adoptado diversas Resoluciones sobre la materia, debiéndose destacar la $\mathrm{Re}$ solución 2625 (XXV) aprobada el 24 de Octubre de 1970, al conmemorarse el XXV aniversario de la entrada en vigencia de la Carta de San Francisco.

(1) Ver al respecto la obra de Ruth B. Russell "A History of the United Nations Charter". Brookings Institution, WWashington, 1958. Página 206.

(2) El tërmino "trabajo permanente para todos" fue objetado en la Conferencia de San Francisco por la delegación de los Estados Unidos de América, la cual propuso en su lugar la frase "altos y estables niveles de empleo". El término "pleno empleo se consideraba no realista y la delegación norteamericana temia que sentara las bases de una intervención de Naciones Unidas en materia de jurisdicción doméstica. Ver al respecto la obra de GOODRICH, HAMBRO y SIMONS "Charter of the United Nations" Columbia University Press. New York y Washington. 1969. Capitulo IX. Página 372. 
La Resolución 2625 (XXV) ha proclamado la obligación de los Estados de cooperar entre sí, de conformidad con la Carta, para promover el crecimiento económico en todo el mundo, y particularmente, en los países en desarrollo.

La evolución descrita en la formulación del Principio de Cooperación ha sido de particular trascendencia en el Derecho Internacional. El Derecho Internacional clásico tenía como objeto fundamental el mantenimiento de la paz y la seguridad internacionales. De dicho objeto derivaba la proscripción del recurso a la fuerza y a la amenaza del uso de ésta. El Derecho Internacional contemporáneo enfatiza que el logro de este objeto implica el crecimiento económico. Por tanto, los Estados tienen hoy no sólo la obligación de no recurrir a la fuerza ni a la amenaza del uso de ésta en la solución de las controversias internacionales, sino además, la obligación de cooperar entre si para lograr el crecimiento económico, particularmente, en los países en desarrollo.

No menos importante es la precisión que esta evolución implica en el Principio de la Igualdad Soberana de los Estados, principio fundamental del Derecho Internacional clásico. Este Principio es plenamente válido hoy en cuanto se refiere a la igualdad jurídica' de los sujetos principales del Derecho Internacional, reconociéndose sin embargo su desigualdad en cuanto a desarrollo económico y social. Los Estados tienen hoy la obligación de cooperar en la lucha contra el subdesarrollo y en el logro de una auténtica soberanía externa económica y social de los paises en desarrollo. El Derecho Internacional contemporáneo reconoce asi la categoría particular de "paises en desarrollo" y establece una serie de normas en su favor.

Casi cuatro décadas después de la entrada en vigor de la Carta de San Francisco, y luego de catorce años de aprobada la Resolución 2625 (XXV), la mayoría de los países en desarrollo se encuentran en una grave situación financiera y monetaria que parece postergar indefinidamente su desarrollo. Sólo los paises de América Latina adeudan más de trescientos sesenta millones de dólares. Unicamente el pago de los intereses de dicha deuda implica la postergación a largo plazo del desarrollo de estos países. 
El organismo encargado de promover la cooperación monetaria y financiera internacional es el Fondo Monetario Internacional. En la segunda mitad del presente siglo dicho organismo internacional ha desempeñado una importante labor en la aplicación del Principio de Cooperación entre los Estados en la esfera de su competencia. Incluso a partir de los agudos transtornos que aparecieron en la economía mundial a partir de 1973, el FMI tuvo que actuar en función de fines y objetivos que iban más allá de aquellos para los cuales habia sido originalmente creado.

Sin embargo su labor ha merecido graves criticas por parte de los paises en desarrollo. En el presente articulo nos referimos brevemente a tres críticas principales: La distribución del poder votante: la ausencia de ligazón entre la creación y distribución de Derechos Especiales de Giro y el proceso de desarrollo; y la condicionalidad en el uso de los recursos del Fondo.

\section{El Fondo Monetatio Internacional}

Constitu'do en diciembre de 1945 por veintinueve Estados, cuenta hoy con más de ciento cuarenta Estados miembros. Entre sus fines cabe destacar el fomento de la estabilidad cambiaria; el coadyuvar al establecimiento de un sistema multilateral de pagos para las transacciones corrientes que se realicen entre los Estados miembros, y a la eliminación de las restricciones cambiarias que entorpezcan la expansión del comercio mundial (3).

Para cumplir con sus fines, se dotó al Fondo Monetario Internacional de un capital inicial cercano a los siete mil millones de dólares americanos, constituido por cuotas aportadas por cada Estado miembro. Cada Estado debia abonar el veinticinco por ciento en oro y el resto en su respectiva moneda nacional.

Las cuotas de los Estados miembros han sido aumentadas sucesivamente (4). Hoy el total de cuotas sobrepasa los cincuentai-

(3) Articulo Primero del Convenio Constitutivo del Fondo Monetario Internacional.

(4) N. del A. En 1959 las cuotas se aumentaron en un cincuenta por ciento. En 1965 en un veinticinco por ciento. En 1970 otro veinticinco por ciento. A raiz del aumento de los precios del petróleo determinado en 
ocho mil millones de Derechos Especiales de Giro - DEG-. En febrero de 1983, el Comité Interino del FMI en el Octavo Examen General, recomendó un aumento de cuotas a noventa mil millones de DEG, frente a los ciento veinticinco mil millones reclamados por los países en desarrollo. Ello generó un profundo desaliento entre los representantes de estos Estados, los cuales aspiran a alcanzar el cuarentaicinco por ciento del capital del Fondo. $-$

Cabe destacar que la cuota de cada Estado miembro determina su participación en las asignaciones de Derechos Especiales de Giro.

\section{1. Distribución del poder votante en el FMI}

Los órganos del Fondo Monetario Internacional son la Junta de Gobernadores, el Comité Directivo, y el Director Gerente. Cada Estado miembro designa un Gobernador y un suplente como integrantes de la Junta de Gobernadores. Asi la Junta de Gobernadores representa a todos los Estados miembros y se halla investida de todas las facultades y atribuciones del organismo. Adopta sus decisiones mediante el sistema del voto ponderado: Cada Gobernador cuenta con el número de votos que corresponde a su Estado.

A diferencia de la Junta de Gobernadores que debe reunirse por lo menos una vez al año, el Comité Directivo se mantiene en sesión permanente en Washington. Está integrado por veintiún Directores Ejecutivos nombrados de la siguiente manera: Quince son nombrados por quince grupos de Estados Miembros; es decir, cada grupo nombra un Director. Uno es nombrado por el Reino de Arabia Saudita, dada su condición de Estado Miembro acreedor (5), y los cinco Directores Ejecutivos restantes son nombrados por los cinco Estados de cuota más elevada: Los Estados

1973, el FMI acordó un aumento del 32.5 por ciento. Por último, en diciembre de 1978 se acordó un aumento general del cincuenta por ciento, $y$ un aumento especial en las cuotas de once Estados miembros.

(5) N. dei A. El Reino de Arabia Saudita fue el principal acreedor durante el periodo $1976-78$. 
Unidos de América, el Reino Unido, la República Federal de Alemania, Francia y Japón.

El Comité Directivo designa al Director Gerente, el mismo que ejerce la presidencia del Comité. Tiene la facultad de decidir cualquier cuestión de interpretación de los artículos del Convenio Constitutivo, ya sea que el conflicto de interpretación surja entre dos o más Estados miembros, o entre uno de éstos y el Fondo. No obstante, las decisiones del Comité Directivo en esta materia están sujetas a la posibil:dad de apelar ante la Junta de Gobernadores (6). El Comité Directivo tiene a su cargo la gestión de las operaciones generales del Fondo, aprueba las consultas con los Estados miembros, efectúa estudios sobre temas de importancia para los Estados integrantes, y tiene a su cargo cuestiones normativas y asuntos administrativos. De otro lado, debe presentar informes anuales a la Junta de Gobernadores.

Esta estructura organizativa ha sido considerada "desequilibrada" por los paises en desarrollo, cuyos representantes han hecho hincapié en que el poder votante "está en función del poder económico y político" y en el hecho que "cinco miembros principales pueden dominar la evolución de la política monetaria internacional" (7).

1I. 2. Creación y distribución de Derechos Especiales de Giro $y$ el Proceso de Desarrollo

El sistema de Derechos Especiales de Giro fue creado mediante la Primera Enmienda al Convenio Constitutivo del Fondo Monetario Internacional, aprobada en 1968. Los antecedentes de este sistema se encuentran en las lineas de crédito utilizables automáticamente de la Unión Europea de Pagos, e incluso en las propuestas de Keynes en 1943.

(6) SORENSEN, Max ... Manual de Derecho Internacional Público. Fondo de Cultura Económica. México, 1978, Capítulo X. Página 576.

(7) Documento TD/B/AC.32/1.1. Informe de la Reunión de Expertos de Paises en Desarrollo sobre la reforma del Sistema Monetario Internacional. Abu Dhabi, junio de 1980. Párrafo 16). 
Los Derechos Especiales de Giro constituyen un activo cie reserva primario. Originalmente su valor fue equivalente al del Dólar Americano. Con el fin de mantener su estabilidad, hoy los Derechos Especiales de Giro se valoran en función de una "cesta" de cinco monedas (Dólar Americano, Libra Esterlina, Marco Alemán, Franco Francés y Yen Japonés).

Los Derechos Especiales de Giro aspiran a convertirse en el principal activo de reserva del sistema monetario internacional. Su creación tiene lugar a partir de una propuesta del Director Gerente del Fondo, propuesta que éste formula cuando considera que existe consenso entre los Estados miembros de aumentar las reservas globales. Es decir, se trata de controlar intencionalmente la creación de reservas, sobre la base de un consenso internacional sobre las necesidades globales.

En Diciembre de 1978, el Director Gerente del Fondo propuso a la Junta de Gobernadores la asignación de doce mil millones de DEG, a razón de cuatro mil millones durante los años 1979, 1980 y 1981. La propuesta fue aprobada por la Junta.

Los DEG se distribuyen a cada Estado miembro en un porcentaje uniforme de sus cuotas. Los paises en desarrollo vienen reclamando una mayor creación de DEG y una distribución adecuada de los mismos para convertirlos en un eficaz instrumento de ayuda al desarrollo. Los representantes de los Estados desarrollados se han opuesto a esta demanda, señalando que las medidas propuestas serian perjudiciales para el sistema monetario internacional, y poniendo el acento en sus efectos inflacionarios (8). Lo cierto es que parece aún lejana la ligazón de la creación de DEG y el desarrollo.

En la actualidad, los DEG representan sólo un tres por ciento de la liquidez internacional. Con el objeto que el régimen de reserva del sistema monetario internacional se base en los DEG.

(8) N. del A. Los economistas españoles Manuel y Félix Varela consideran que sobre una creación anual de diez mil millones de DEG, corresponderia a los paises en desarrollo unos dos mil quinientos millones. Dicha cifra se multiplicaría por cuatro si la creación de liquidez se repartiese entre los paises en desarrollo de acuerdo a sus exigencias. 
los paises en desarrollo han planteado "la introducción inmediata de reformas en las características de los DEG, y una asignación regular, adecuada e ininterrumpida de éstos" (9). Por asignación adecuada debemos entender una distribución vinculada al desarrollo, en general, y especificamente, orientada a satisfacer "las necesidades de los Estados miembros en lo referente a los pagos" (10).

\section{3. La condicionalidad en el uso de los recursos del Fondo}

No obstante la importancia de los aspectos descritos, ninguno ha sido tan criticado como la condicionalidad en el uso de los recursos del Fondo. Suele señalarse que el Fondo impone condiciones rigidas e inflexibles, que suelen carecer de fundamentos económicos claros, y que muchas veces resultan contraproducentes. Es interesante observar que los programas de estabilización de muchos paises en desarrollo, que han sido aprobados por el Fondo, se basan en una serie de medidas económicas muy similares. Más allá de las diferencias existentes en la estructura de las economias de distintos paises, y de las diversas circunstancias coyunturales por las que atraviesan, el Fondo prescribe politicas muy parecidas, si no similares.

Los paises en desarrollo vienen criticando que en la evaluación de las politicas macroeconómicas de los países miembros, el Fondo utiliza un marco uniforme y rígido, basado principalmente, en un análisis de los factores que influyen en la oferta y en la demanda de liquidez (11). Otra crítica importante reside en que el Fondo no se preocupa por determinar las causas de los problemas de Balanza de Pagos, ni en distinguir si éstas son de origen endógeno o exógeno, centrando únicamente su atención en determinar el carácter, transitorio o permanente, de los desequilibrios.

(9) Documento TD/B/AC.32/L.1. citado anteriormente. Párrafo 32.

(10) Loc. cit. Párrafo 34.

(11) N. del A. Para un análisis de las criticas al FMI conviene consultar el articulo de NOWZAD, Bahram "The IMF and its Critics" en Essays in International Finance No 146. Princeton University. December 1981. 
Sin embargo la crítica principal de los paises en desarrollo y de sectores crecientes de los Estados desarrollados y de algunos Organismos Internacionales, reside en el hecho que el Fondo sacrifica conscientemente el desarrollo en aras de la estabilidad.

La condicionalidad impuesta por el FMI en la concesión de sus préstamos ha sido considerada "incompatible con las exigencias del desarrollo y los ajustes estructurales" por los Jefes de Estado y de Gobierno de los Países No Alineados (12). Estos han destacado asimismo que "los programas de reajuste deberian ser coherentes con los arreglos politicos y sociales de cada país, así como con el tipo de proceso de reajuste que los paises en desarrollo pueden adoptar con miras a estimular su propio proceso de desarrollo" (13).

Pareceria que estas críticas a la condicionalidad en el uso de los recursos del Fondo han llegado incluso al Congreso de los Estados Unidos de América: La Ley Pública No 98-181 promulgada recientemente, aprueba el aumento de la cuota de dicha potencia al FMI, y establece en sus enunciados dos conceptos importantes: El primero consiste en que los recursos que se proveen al FMI "deben ser usados para apoyar politicas pro-crecimiento". El segundo, se refiere al hecho que "las politicas económicas prescritas por el FMI pueden estar siendo dañinas para el crecimiento económico (14).

\section{Conclusión}

Las críticas de los países en desarrollo al Fondo Monetario Internacional señaladas en el presente articulo, parecen tener consistencia suficiente para ameritar su análisis al interior del Fondo $y$ en el seno de la comunidad internacional organizada.

(12) Documento NAC/CONF. 7/DOC..6/Rev. 3, presentado por el Grupo de Redacción ante la última Conferencia Cumbre de los Paises No Alineados. Párrafo 42.

(13) Loc. cit. Párrafo 45.

(14) SALAZAR OLIVARES, Raúl..." El FMI y las perspectivas de Endeudamiento Externo". EN: Debate No 25. Lima, marzo de 1984. Página 26. 
En varias ocasiones, las medidas económicas recomendadas por el Fondo en los Acuerdos suscritos con paises en desarrollo, han reforzado las tendencias de recesión asociadas con rápidos aumentos de la inflación en estos paises. La opinión generalizada en los paises en desarrollo relativa a que las politicas económicas prescrtas por el Fondo son incompatibles con las exigencias del desarrollo, plantea la necesidad que dicho Organismo Internacional reformule sus politicas globales.

Dicha reformulación debe comprender el estudio de la posibilidad de un nuevo incremento de las cuotas, que eleve la participación de los paises en desarrollo en el capital del Fondo, y, por ende, su poder votante. Parece necesaria también una mayor y adecuada ligazón entre la creación y distribución de los Derechos Especiales de Giro y la ayuda al desarrollo.

Principalmente, el Fondo debe revisar la política de condicionalidad en la utilización de sus recursos, con el objeto de establecer politicas más flexibes, que atiendan a las caracteristicas diferentes de las diversas economias nacionales, y a las particulares situaciones coyunturales por las que atraviesan; y en especial, que estén en función del desarrollo económico de los paises a los cuales se aplican.

Sin embargo, la vigencia plena del Principio de Cooperación en la esfera del sistema monetario y financiero internacional, exige más que estas reformas en la estructura y en las políticas del Fondo. Debe pensarse en la creación de un sistema monetario internacional que esté diseñado integramente en función del desarrollo. Ello puede parecer utópico. Pero recordemos, con Manuel Medina Ortega, que "la misma Organización de Naciones Un:das es, precisamente, una utopia milenaria hecha realidad". 


\title{
PROBLEMAS JURIDICOS DEL SOBREENDEUDAMIENTO DE LOS PAISES EN DESARROLLO \\ RELEV!ANCIA ACTUAL DE LA DOCTRINA DE LAS DEUDAS ODIOSAS
}

\author{
Günter Frankenberg \\ Rolf Knieper (*)
}

Este articulo pretende discutir la parte del problema del endeudamiento que está compuesta, fundamentalmente, por créditos utilizados para inversiones de dudoso valor desde el punto de vista del desarrollo, trabajando en base a las llamadas "deudas odiosas" del Derecho Internacional, y su vinculación con la teoría y práctica del desarrollo económico.

El propósito del trabajo es contribuir a la solución del actual problema del endeudamiento y a su prevención para el futuro.

Sus presupuestos básicos son, en primer lugar, que solamente mediante la incorporación de criterios objetivos que puedan ser inferidos del debate internacional sobre el desarrollo, es posible evitar una situacón aún más catastrófica; y, en segundo lugar, que el valor de desarrollo de los bienes exportados al Tercer Mundo, es un riesgo compartido por el proveedor y por el comprador conjuntamente.

(*) Gunter Frankenberg es Doctor en Derecho y Doctor en Filosofia de la Universidad de Frankfurt. En la actualidad es Profesor Visitante en la Facultad de Derecho de la Universidad de Harvard. Rolf Knieper es Doctor en Derecho y profesor de la Universidad de Bremen. Actualmente reside en Bangui, donde es Asesor Legal de la Presidencia de la República de Africa Central. El artículo ha sido traducido por Fernando de Trazegnies G.

E1 traductor no se solidariza necesariamente con todas las opiniones vertidas en este artículo por sus autores; e incluso considera que existen abiertas discrepancias o matices profundos entre sus propias ideas jurídicas y los planteamientos del trabajo. Sin embargo, considera que este estudio es un hito importante en la historia del Derecho Internacional $y$ que tiene un valor extraordinario como estimulante de una nueva re- 